\title{
O DISCURSO DA EMENDA N. 95/2016 NO CONTEXTO DA GOVERNAMENTALIDADE NEOLIBERAL
}

\author{
EL DISCURSO DE LA ENMIENDA EM EL CONTEXTO DE LA NEOLIBERAL \\ GUBERNAMENTALIDAD
}

\section{THE DISCOURSE OF AMENDMENT N. 95/2016 IN THE CONTEXT OF NEOLIBERAL GOVERNMENTALITY}

\author{
Silvia Cristina Barbosa da SILVA ${ }^{1}$ \\ Paula Ramos de OLIVEIRA ${ }^{2}$
}

RESUMO: O texto apresenta uma análise sobre o discurso da criação da Emenda Constitucional n. 95/2016 em uma perspectiva foucaultiana. Os princípios do Novo Regime Fiscal (NRF) determinam uma redução dos investimentos nos setores da saúde e da educação. Diante disso, busca-se identificar o contexto da Emenda na conjuntura de uma governamentalidade que está relacionada ao modo como os sujeitos são conduzidos, bem como apontar relações sobre a emergência de uma governamentalidade neoliberal em que o Estado tende a sofrer uma maior influência da iniciativa privada no setor educacional. Considera-se a proposta desta Emenda uma biopolítica, pelo fato de orientar os corpos dos sujeitos e conduzilos no processo de sua constituição em uma relação de poder e controle.

PALAVRAS-CHAVE: Poder. Governamentalidade. Biopolítica. Resistência.

RESUMEN: El texto presenta un análisis sobre el discurso de la creación de la Enmienda Constitucional n. 95/2016 em una perspectiva foucaultiana. Los principios del Nuevo Régimen Fiscal (NRF) determinan uma reducción de las inversiones em los sectores de salud y educacion. Ante esto, buscamos identificar el contexto de la Enmienda em la coyuntura de una gubernamentalidade relacionada con la forma en que se conducen los temas, así como señalar las relaciones sobre el surgimento de uma gubernamentalidade neoliberal em la que el Estado tiende a estar más influenciado por la iniciativa privada en el sector educativo. La propuesta de esta Enmienda se considera una biopolítica, porque guia los cuerpos de los sujetos y los guia en el proceso de su constituición em uma relacíon de poder y control.

PALABRAS CLAVE: Poder. Gubernamentalidad. Biopolítica. Resistencia.

\footnotetext{
${ }^{1}$ Universidade Estadual Paulista (UNESP), Araraquara - SP - Brasil. Doutoranda no Programa de Pós-Graduação em Educação Escolar. ORCID: https://orcid.org/0000-0003-0241-5173. E-mail: silvia.barbosa014@gmail.com

2 Universidade Estadual Paulista (UNESP), Araraquara - SP - Brasil. Professora doutora assistente no departamento de Educação. Pós-doutorado pela Universidade de Lisboa. Professora e orientadora (Mestrado Acadêmico e Doutorado) no Programa de Pós-Graduação em Educação Escolar (UNESP/Araraquara) e do Programa de Mestrado em Filosofia (PROF-FILO/núcleo UFSCar). ORCID: https://orcid.org/0000-0001-96205964. E-mail: paula-ramos@uol.com.br
} 
ABSTRACT: The text presents an analysis on the discourse on the creation of Constitutional Amendment n. 95/2016 in a Foucauldian perspective. The principles of the New Fiscal Regime $(N R F)$ determine a reduction in investments in the health and education sectors. Therefore, we seek to identify the context of the Amendment in the conjuncture of a governmentality that is related to the way subjects are conducted, as well as to point out relations about the emergence of a neoliberal governmentality in which the State tends to be influenced by the private initiative, in the education sector. The proposal of this Amendment is considered biopolitics, because it guides the bodies of the subjects and leads them in the process of their constitution in a relationship of power and control.

KEYWORDS: Power. Governmentality. Biopolitics. Resistance.

\title{
Introdução
}

Analisar um documento exige uma compreensão sobre o seu discurso e seus efeitos nas práticas discursivas, que diz respeito a um conjunto de enunciados que "moldam nossas maneiras de constituir o mundo, de compreendê-lo e de falar sobre ele" (VEIGA-NETO, 2011, p. 93). Compreender esse discurso consiste em uma constatação do processo de objetivação sobre os sujeitos que o documento implica por meio da normalização. Nesse contexto:

\begin{abstract}
Por mais que o discurso seja aparentemente bem pouca coisa, as interdições que o atingem revelam logo, rapidamente, sua ligação com o desejo e com o poder. Nisto não há nada de espantos, visto que o discurso - como a psicanálise nos mostrou - não é simplesmente aquilo que manifesta (ou oculta) o desejo; é, também, aquilo que é objeto do desejo; e visto que - isto a história não cessa de nos ensinar - o discurso não é simplesmente aquilo que traduz as lutas ou os sistemas de dominação, mas aquilo por que, pelo que se luta, o poder do qual nós queremos apoderar (FOUCAULT, 2008, p. 9-10).
\end{abstract}

O discurso da emenda constitui uma prática discursiva por sua normatização, e nessa circunstância surgem às práticas não discursivas que representam o sentido e a efetivação do documento no exercício de sua prática. O discurso da Emenda n. 95/2016 (EC) determina uma relação de poder que envolve a vida, estruturada pelo biopoder, no modo de ação sobre os sujeitos, em como os indivíduos têm seu próprio corpo estruturado em uma relação de poder que:

Ao contrário, para Foucault, o poder não é algo que se toma, algo que se tem ou se conquista, mas algo que se exerce. Com efeito, não existe o Poder por lado e os indivíduos por outro, mas indivíduos exercendo poderes no que ele chama de arte de governo. 'Governo' não quer dizer, nesta ótica, aparato estatal, mas o modo como se dirige, em qualquer âmbito, a conduta dos indivíduos. Governar, diz Foucault, é estruturar o possível de ação dos outros. De modo que o exercício do poder é um modo como certas ações estruturam 
o campo de outras possíveis ações. Assim, se afirma o caráter produtivo, não apenas repressivo do poder (KOHAN, 2011, p. 72).

\section{A Emenda n. 95/2016 inserida na educação maior}

Veiga-Neto (2011), na obra intitulada "Foucault \& a Educação", realiza um estudo sobre as obras de Michel Foucault e relaciona os conceitos que o filósofo propõe ao contexto disciplinador da instituição escolar, uma vez que o filósofo não teve seus escritos voltados diretamente para a escola. $\mathrm{O}$ autor argumenta que na perspectiva foucaultiana:

Os discursos não são, portanto, resultado da combinação de palavras que representam as coisas no mundo [...] Ao contrário, "os discursos formam sistematicamente os objetos que falam. Certamente os discursos são feitos de signos; mas o que eles fazem é mais que utilizar esses signos para designar coisas. É esse mais que os torna irredutíveis à língua e ao ato de fala" (VEIGANETO, 2011, p. 93).

Nessa designação o discurso constitui sua materialidade no próprio objeto, no qual configura o Novo Regime Fiscal (NRF). Este determina que os recursos públicos do setor educacional adquiram um limite, um teto em seus investimentos. E, assim, as instituições escolares se veem diante de uma cesura estipulada por vinte anos. Nesse contexto, as leis educacionais com suas metas e seus princípios são alteradas frente a esse controle, no qual estão inseridas em uma educação maior, que de acordo com Gallo (2008), na obra "Deleuze \& a Educação", situa:

A educação maior é aquela dos planos decenais e das políticas públicas de educação, dos parâmetros e das diretrizes, aquela da constituição e da Lei de Diretrizes e Bases da Educação Nacional, pensada e produzida pelas cabeças bem pensantes a serviço do poder. A educação maior é aquela instituída e que quer instituir-se, fazer-se presente, fazer-se acontecer (GALLO, 2008, p. 64).

Nesse sentido, essa EC também se integra nessa educação maior por ser uma política pública, com estratégias estipuladas que envolvem todo o cenário educacional do país, uma vez que ela também está fundamentada na Constituição Federal tendendo, deste modo, a ser concretizada na Lei de Diretrizes e Bases da Educação Brasileira (LDB), documento que rege a normatização educacional do país. 


\section{O propósito da Emenda n. 95/20016}

A EC promulgada em 15 de dezembro de 2016 propõe um teto em seu NRF. Este teto é um limite de gastos da União com os investimentos nos setores da saúde e da educação por vinte anos, previstos até o ano de 2037, está descrito na Constituição Federal nos artigos 106 até 114, destacaremos aqui algumas desses artigos:

Art. 110. Na vigência do Novo Regime Fiscal, as aplicações mínimas em ações e serviços públicos de saúde e em manutenção e desenvolvimento do ensino equivalerão:

I - no exercício de 2017, às aplicações mínimas calculadas nos termos do inciso I do $\S 2^{\circ}$ do art. 198 e do caput do art. 212, da Constituição Federal;

II - nos exercícios posteriores, aos valores calculados para as aplicações mínimas do exercício imediatamente anterior, corrigidos na forma estabelecida pelo inciso II do $\S 1^{\circ}$ do art. 107 deste Ato das Disposições Constitucionais Transitórias (BRASIL, 2016).

O artigo 198 da Constituição Federal refere-se à seção II da Saúde, na qual aborda sobre as diretrizes que compõe o Sistema Único de Saúde, além disso o artigo 212 menciona a porcentagem do investimento para a educação. Sobre esta legislação no campo educacional, tem-se que:

Art. 212. A União aplicará, anualmente, nunca menos de dezoito, e os Estados, o Distrito Federal e os Municípios vinte e cinco por cento, no mínimo, da receita resultante de impostos, compreendida a proveniente de transferências, na manutenção e desenvolvimento do ensino (BRASIL, 2016).

No entanto, o artigo 111 da EC apresenta uma limitação maior em relação aos investimentos na educação, ao definir que a União, ao destinar recursos para esta área, deve se referenciar ao ano anterior. Tal cálculo só deve ter alteração anual em combinação com a inflação acumulada segundo o Índice Nacional de Preços ao Consumidor Amplo (IPCA), em que a receita de imposto só poderia ser contada dezoito porcento.

Art. 111. A partir do exercício financeiro de 2018, até o último exercício de vigência do Novo Regime Fiscal, a aprovação e a execução previstas nos §§ $9^{\circ}$ e 11 do art. 166 da Constituição Federal corresponderão ao montante de execução obrigatória para o exercício de 2017, corrigido na forma estabelecida pelo inciso II do $\S 1^{\circ}$ do art. 107 deste Ato das Disposições Constitucionais Transitórias (BRASIL, 2016).

Durante vinte anos, como relata a proposta, as “despesas" públicas terão apenas suas correções inflacionais ajustadas, não havendo, assim, aumentos reais nestes setores de suma importância, priorizando o pagamento de dívida pública e secundarizando Educação e Saúde. Neste jogo discursivo de valores, encontra-se uma disputa entre o campo político neoliberal e o campo de formações da Educação quando se investiga a presença de discursos que marcam concepções sobre esta medida. Ao se procurar nesta EC os itens lexicais "despesa" e 
"investimento", são encontrados apenas o primeiro. Este fato demostra a força do discurso neoliberal na esfera política pública que rege a Educação atual no país. A educação é vista como mercadoria, como objeto de trocas comerciais, pois possui despesas. O campo político silencia o discurso da Educação como investimento amplo na vida dos sujeitos, objetivando-os, constituindo o sujeito também como objeto.

De acordo com Silva e Bittencurt (2017), a EC pode ser interpretada por duas correntes: a primeira defende a ideia da busca pela salvação das contas públicas, da dívida externa a fim de cobrir déficits, e que ao fixar os investimentos o país alcançará um equilíbrio financeiro; a segunda, por outro lado, apresenta a ideia de que a EC tende a fortalecer os limites para os gastos com políticas públicas e sociais e, desse modo, pode prejudicar as classes menos favorecidas ao colocar em risco o direito, acesso e permanência na educação. Porém, para estes autores, nem a corrente a favor e nem a corrente contra são adequadas. Eles argumentam que tanto o Executivo, quanto o Legislativo podem propor acréscimos para os investimentos quando necessário, pois o documento não apresenta tanta rigorosidade, além de o Executivo ter o poder de criar medidas provisórias de acordo com necessidades.

Neste mesmo contexto, outro ponto que pode ser debatido é o item lexical "extrapolação". Podendo os poderes políticos intervirem em situações de urgência, o que se considera como extrapolação varia e os limites se tornam mais subjetivos, cabendo à valoração político-ideológica.

Assim, esta EC deixa claro que o congelamento dos gastos sociais se refere ao pagamento de dívidas do Estado, fato que reduz os investimentos com políticas de ações afirmativas e políticas públicas que visam ao reparo de danos a grupos vulneráveis, desse modo, o Estado modifica seu papel ao agir com austeridade sobre a população.

\section{A Governamentalidade e a Emenda n. 95/2016}

Foucault (2008), na obra "Segurança, Território e População", destaca o conceito de "governar" estruturado em uma tríade: Soberania, Disciplina e Gestão governamental. A primeira refere-se ao período monárquico, e esteve relacionada ao regime de uma arte de governar do rei por meio das leis e também de uma normalização, em que o território era o alvo. A segunda retoma o período moderno em que os corpos dos indivíduos estavam inseridos em um processo de individualização, por meio da disciplina. E o último termo diz respeito ao período contemporâneo, em que a questão da segurança se exerce sobre um conjunto da população, que se torna objeto e sujeito de um mecanismo de segurança que se exerce ao 
controlá-la através saberes desenvolvidos pela ciência no período moderno. Desse modo, o conceito de governamentalidade diz respeito a uma tecnologia de governo, um poder sobre os indivíduos, associado ao aparecimento das populações como problema político que visa a um controle sobre os corpos na dinâmica social sob o aspecto de uma "biopolítica".

Por outro lado, Foucault destaca que o caráter soberano e disciplinar não se extingue na contemporaneidade. Estes ainda produzem corpos obedientes e dóceis, inseridos em uma relação de poder sobre a vida (que caracteriza o biopoder), e representam a maneira como os corpos são gerenciados pela estrutura social. Esse gerenciamento da população é formulado pela biopolítica, uma força que regula a população e os corpos em multidão. Esta medida de congelamento de investimentos através de políticas públicas efetua uma concepção da biopolítica, pois a EC produz esse efeito regulador sobre os sujeitos.

Prado Filho (2006), em “A história da governamentalidade”, retrata o processo histórico de tal conceito e o define pela concepção de governo. Segundo o autor, a ideia de governo não se restringe à política de Estado e sim de um mecanismo governo que influência as condutas dos indivíduos. Nesse sentido, o governo "incide sobre corpos individuais e coletivos regulando, marcando, normalizando e individualizando: induz efeitos de subjetividade; concerne à vida dos indivíduos" (PRADO FILHO, 2006, p. 19). A governamentalidade propõe o questionamento sobre o modo pelo qual o sujeito é conduzido em um:

[...] um conjunto de estratégias e procedimentos de poder emergentes nos séculos XVII e XVIII, que toma como alvo os indivíduos e as populações, utilizando-se de dispositivos de saúde e segurança e apoiando-se na economia política como forma predominante de conhecimento, tendendo a multiplicar uma série de aparelhos e saberes específicos relativos às práticas de governo (PRADO FILHO, 2006, p. 42).

A palavra "governar" possui sentido amplo, uma ação de administrar algo. Por isso, na perspectiva foucaultiana não se governa nem um Estado e nem um território, o que se governa são os sujeitos. Assim, "governar" em um sentido moral representa "conduzir alguém" e também ““'impor um regime”, impor um regime a um doente: o médico governa o doente, ou o doente que se impõe certo número de cuidados se governa" (FOUCAULT, 2008, p. 163).

A governamentalidade, deste modo, consiste em um ato de governar como uma tecnologia, a fim de regular a vida da população. Nesse contexto, a EC também governa, pois conduz os sujeitos a viverem diante de uma cesura imposta pela própria emenda.

Veiga-Neto (2010), no artigo Gubernamentalidad neoliberal: implicaciones para la educación, relata sobre o deslocamento da ênfase da soberania sobre o território para a ênfase da soberania sobre a população, em que a arte de governar não esteve mais restrita na figura do 
soberano e sim sobre o Estado, no qual passou a se preocupar com a regulação da população por meio das políticas públicas. Desse modo, o Estado é problematizado e não mais o governante, rei-soberano. De acordo com Veiga-Neto (2010):

Es a partir de estas constataciones que Foucault propone el concepto de gubernamentalidad, que hace referencia tanto a una razón o táctica de gobierno, una racionalidade gobernamental que descubre la economia, e que hace de la población su principal objetivo, como "al contacto entre las tecnologias de dominación de los otros y las [tecnologias] dirigidas a la [dominación] del yo (p. 215).

A governamentalidade constitui essa racionalidade do Estado que visa regular a população através de um mecanismo de segurança, que configura os saberes como estatística, demografia, economia entre outros, saberes que envolvem um poder, uma ação de biopoder sobre a população. Mediante o poder exercido pelo Estado, este se vê insatisfeito em relação a uma demasiada racionalidade em que a própria razão de Estado é questionada e, assim, surge:

[...] una crítica que descubre que gobernar demás es irracional, pues es antieconómico y frustrante; una crítica que se manifiesta como un horror al Estado. Así, en la perspectiva de Foucault el liberalismo es menos una fase histórica, una filosofía política o un sistema económico, y mas un refinamiento de arte de gobernar, en el que el gobierno, para ser más económico, se convierte em más delicado y sutil, de modo que, para "gobernar más es necesario gobernar menos" (VEIGA-NETO, 2010, p. 218).

A instituição escolar na modernidade visa a uma fabricação do sujeito, no entanto, a perspectiva foucaultiana tende a romper com esse ideal na proposição de um sujeito capaz de se autogovernar, em uma luta e resistência diante do processo de subjetivação.

O liberalismo tenta conciliar essa governamentalização do estado com a liberdade econômica, com a própria liberdade dos indivíduos. Ele se ocupa “del gobierno de la sociedade; una sociedad formada por sujetos que son, cada uno y al mismo tempo, objeto (gobernado desde fuera) y socio (sujeto auto-gobernado) del gobierno" (VEIGA-NETO, 2010, p. 218).

O autor também comenta que o neoliberalismo apresenta uma nova configuração do liberalismo, porém não atua como um inimigo do Estado, pois este não tem sua função diminuída, o que diferencia são as novas formas de saberes e competências que auxiliam para a expansão das formas avançadas do capitalismo. Nesse sentido, o Estado segue uma lógica empresarial inserido nessa macroeconomia. Por outro lado, o neoliberalismo caracterizado pela mínima presença do Estado contribui para a constituição de um sujeito não mais fabricado e sim mais manipulável, inserido em uma lógica empresarial e diante disso: 
[...] o se privatizan las actividades estatales (lucrativas) o se someten ou se privatizam as atividades estatais (lucrativas), ou se submetem a las actividades (no lucrativas) a la lógica empresarial. Es por eso que los discursos neoliberales insisten en afirmar que el Estado sólo de debe ocupar de algunas atividades "esenciales" como la educación, y la salud; e incluso así encargándose de, como máximo, regularlas (VEIGA-NETO, 2010, p. 224).

Dessa forma, a EC é estruturada em meio a uma lógica financeira no congelamento de investimentos educacionais. Esse controle está imerso na macropolítica de uma educação maior. $\mathrm{O}$ autor, também ressalta a presença de uma educação menor, que configura uma micropolítica que pode ser constituída por ações cotidianas de resistência frente ao controle e regulação da educação maior e assim:

Qualquer luta é sempre resistência dentro da própria rede de poder, teia que se alastra por toda a sociedade e a que ninguém pode escapar: ele está sempre presente e se exerce como uma multiplicidade de relações de forças. E como onde há poder, há resistência, não existe propriamente o lugar da resistência, mas pontos móveis e transitórios que também se distribuem por toda a estrutura social (FOUCAULT, 2013, p. 18).

A resistência está presente nas relações de poder, e esses pontos móveis configuram uma educação menor frente à educação maior que atua em sua prática discursiva, neste caso a educação menor estaria inserida em uma prática não discursiva. Logo, a educação menor visa à produção da diferença, e "se toda educação é um ato político, no caso de uma educação menor, isso é ainda mais evidente, por tratar-se de um empreendimento de revolta e resistência" (GALLO, 2008, p. 67). Tal possibilidade produz uma possível problematização sobre a educação maior que normatiza o discurso da EC.

Gallo (2012) utiliza o termo "governamentalidade democrática" ao contextualizar o Brasil desde o surgimento da Constituição Federal, no processo de redemocratização, inserido em uma intensificação da produção de políticas públicas no país, ele afirma que por meio das leis educacionais o sujeito passa a ser alvo do governo e com a criação da EC constata-se que os sujeitos também se tornam alvo do governo, que visa a uma política neoliberal.

O autor também problematiza o termo "cidadania" presente na Constituição, que tem como princípio a formação de um cidadão governado democraticamente, e questiona se o próprio conceito garante a autenticidade do direito explicitado no documento. Nesse discurso, ser governado é participar dos atos de governo, bem como um assujeitamento no processo de subjetivação integrado nessa governamentalidade. 


\section{Considerações finais}

As condições de produção do discurso também estão relacionadas com as relações de poder e de lugar ocupado pelo sujeito do discurso e pelos interlocutores, o que leva a acreditar que a força do discurso de um locutor é definida pela sua posição social. O discurso político da EC marca, assim, certas formas de conceber os sujeitos e dialoga com determinados tipos de construção ideológica. No entanto, o poder tem em si sempre uma abertura para a resistência, pois a noção de poder na óptica foucaultiana é sempre exercida por sujeitos. Existe uma constante disputa ideológica de realização do poder, influenciando os sujeitos em seus processos de constituição, inseridos em uma governamentalidade, nos mais diversos tempos históricos.

A configuração do Estado na abertura com o mercado financeiro caracteriza a política neoliberal. E as instituições escolares herdam esses preceitos no cumprimento das normas. Um exemplo é a parceria com as editoras, que produzem uma ampla quantidade de livros didáticos para as escolas. Assim, são muitos os investimentos na esfera educacional e, o Estado, com seu olhar neoliberal necessitaria de enfatizar ações para uma melhor distribuição com os gastos na educação.

Pensar sobre a EC e suas consequências sobre a educação envolve uma avaliação sobre sua efetividade a ser realizada a cada triênio. A análise da EC ao longo desse período implicaria em uma escuta dos próprios sujeitos "governados" no contexto escolar. Ao administrar esses recursos investidos na saúde e educação deve-se priorizar uma melhoria na gestão financeira nestes domínios. Considera-se que a problemática em ambos os setores não é a ausência de recursos, mas sim um gerenciamento adequado e viável que supra os direitos dos sujeitos nos âmbitos da saúde e educação.

\section{REFERÊNCIAS}

BRASIL. Emenda Constitucional. n. 95, de 15 de dezembro de 2016. Altera o Ato das Disposições Constitucionais Transitórias, para instituir o Novo Regime Fiscal, e dar outras providências. Diário oficial da República Federativa do Brasil, Brasília, DF, 2016.

FOUCAULT, M. A ordem do discurso. Aula inaugural no Collège de France, pronunciada em 2 de dezembro de 1970. São Paulo: Loyola, 2008.

FOUCAULT, M. Segurança. Território e População. Curso dado no Collège de France (1977-1978). Tradução Eduardo Brandão. São Paulo: Martins Fontes, 2008.

GALLO, S. Deleuze \& a Educação. Belo Horizonte: Autêntica, 2008. 
GALLO, S. Governamentalidade democrática e ensino de filosofia no Brasil contemporâneo. Cadernos de pesquisa, São Paulo, v. 42, n. 145, p. 48-65, jan./abr. 2012. Disponível em: http://www.scielo.br/pdf/cp/v42n145/05.pdf. Acesso em: 29 nov. 2019.

KOHAN, W. O. Infância - Entre Educação e Filosofia. Belo Horizonte: Autêntica, 2011.

PRADO FILHO, K. Michel Foucault: uma história da governamentalidade. Rio de Janeiro: Achiamé, 2006.

SILVA, J. R. P; BITTENCOURT, F. M. Orçamento em discussão. Uma interpretação para o teor dos dispositivos da Emenda Constitucional n ${ }^{\circ}$ 95, 15 de dezembro de 2016, que instituiu o Novo Regime Fiscal com limites com os gastos da União, e considerações sobre sua implementação. Disponível em:

https://www2.senado.leg.br/bdsf/bitstream/handle/id/529648/OED0034.pdf?sequence. Acesso em: 30 nov. 2019.

VEIGA-NETO, A. Gubernamentalidad neoliberal: implicaciones para la educación. Revista Educación y Pedagogía, Medellín, v. 22, n. 58, p. 213-235, set./dez. 2010. Disponível em: http://aprendeenlinea.udea.edu.co/revistas/index.php/revistaeyp/article/view/9748/8965. Acesso em: 29 nov. 2019.

VEIGA-NETO, A. Foucault \& a Educação. Belo Horizonte: Autêntica, 2011.

\section{Como referenciar este artigo}

SILVA, Silvia Cristina Barbosa da; OLIVEIRA, Paula Ramos de. O discurso da Emenda Constitucional n. 95/2016 no contexto da governamentalidade neoliberal. Revista on line de Política e Gestão Educacional, Araraquara, v. 24, n. 1, p. 154-163, jan./abr., 2020. eISSN:1519-9029. DOI: https://doi.org/10.22633/rpge.v24i1.13189

Submetido em: 27/10/2019

Revisões requeridas: 18/11/2019

Aprovado em: 28/12/2019

Publicado em: 06/01/2020 